\title{
Anemia unmasking disseminated endocarditis of four valves
}

\author{
() Marija Mance*, \\ DDaniel Lovrić, \\ Olvica Šafradin, \\ (1)Bojan Biočina, \\ Rajko Ostojić, \\ (D) Jadranka Šeparović \\ Hanževački
}

University of Zagreb School of Medicine, University Hospital Centre Zagreb, Zagreb, Croatia

RECEIVED:

February 28, 2019

ACCEPTED:

March 24, 2019

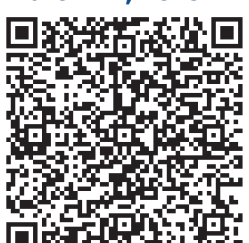

$\square$ Cardiologia Croatica 2019:14(3-4):48.
KEYWORDS: disseminated infective endocarditis, ruptured mitral chordae tendineae, mitral regurgitation, valve vegetations, anemia.

CITATION: Cardiol Croat. 2019;14(3-4):48-9. | https://doi.org/10.15836/ccar2019.48

*ADDRESS FOR CORRESPONDENCE: Marija Mance, Klinički bolnički centar Zagreb, Kišpatićeva 12, HR-10000 Zagreb, Croatia. / Phone: +385-99-7742-627 / E-mail: marija.brestovac@gmail.com

ORCID: Marija Mance, https://orcid.org/0000-0003-1542-2890 • Daniel Lovrić, https://orcid.org/0000-0002-5052-6559 Ivica Šafradin, https://orcid.org/0000-0003-4519-5940 • Bojan Biočina, https://orcid.org/0000-0003-3362-9596 Jadranka Šeparović Hanževački, https://orcid.org/0000-0002-3437-6407

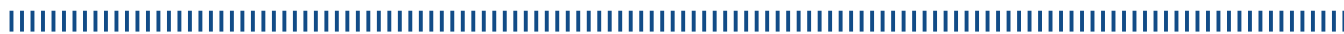

Introduction: Outside of the immunocompromised patient group, infective endocarditis (IE) of all four valves is a rare finding. It is a potentially deadly disease causing multiple complications, as well as a plethora of associated symptoms and clinical signs which can confound early diagnosis and lead to unnecessary testing. ${ }^{1-4}$

Case report: We present 71-year-old male patient who was admitted to the hospital for diagnostic workup of microcytic anemia. Medical history revealed permanent atrial fibrillation and arterial hypertension. In the previous two months he was feeling occasionally feverish, with night sweats and orthopnea. His clinical status showed irregular heartbeats with apical systolic heart murmur, bilateral basal crackles in the lungs, hepatosplenomegaly, scrotal edema and swollen legs. He underwent endoscopy without visible signs of hemorrhage and one tubulovillous adenoma with low grade dysplasia was removed. As plasma M protein was present, further hematologic tests were performed including bone marrow biopsy which was normal. Bone scintigraphy and PET CT showed pathologic accumulation in multiple ribs and vertebrae due to compressive fractures, lytic lesions and spondylodiscitis, in bone marrow and spleen without signs of malignancy as well as enlarged mediastinal, tracheal, axillar and inguinal lymph nodes. Patient was treated with diuretics, digoxin, betablockers, proton pump inhibitors, reimbursement of albumin and blood transfusions. During the third day of hospital stay patient became febrile. Transthoracic and transesophageal echocardiographic examination revealed signs of volume overload, normal ejection fraction, vegetations on all four valves with severe mitral regurgitation (MR) due to ruptured chordae and flail of P2 and P3 segments (Figure 1, Figure 2 and Figure 3), severe tricuspid regurgitation (TR) and pulmonary hypertension (Figure 4, and Figure 5). As Streptococcus gallolyticus was isolated in hemocultures, antibiotic therapy was modified according to antibiogram and diagnosis. Coronary artery stenosis was ruled out by MSCT coronary angiography. Patient was admitted to cardiac surgery and a successful mitral valve replacement with a bioprosthetic valve and surgical debulking of vegetations at other valves was performed. Postoperative echocardiography showed good position of mitral bioprosthesis without paravalvular MR, intermediate aortic regurgitation and severe TR without visible vegetations. In a two-year follow up patient is clinically stabile and remains in NYHA II class.

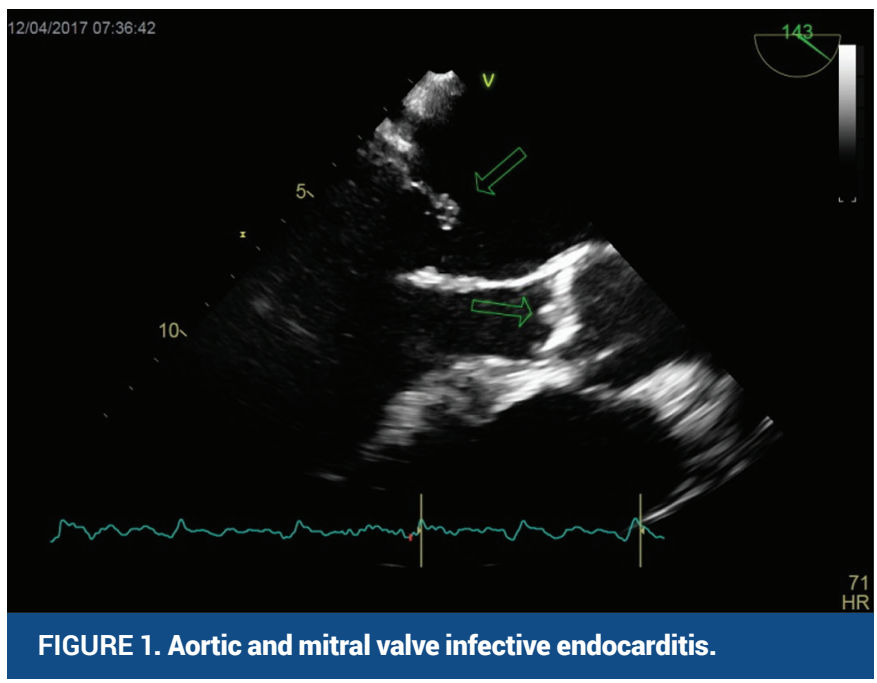

10. hrvatski dvogodišnji ehokardiografski kongres s međunarodnim sudjelovanjem $10^{\text {th }}$ Croatian Biennial Echocardiography Congress with International Participation Poreč, 16. do 18.5.2019. 

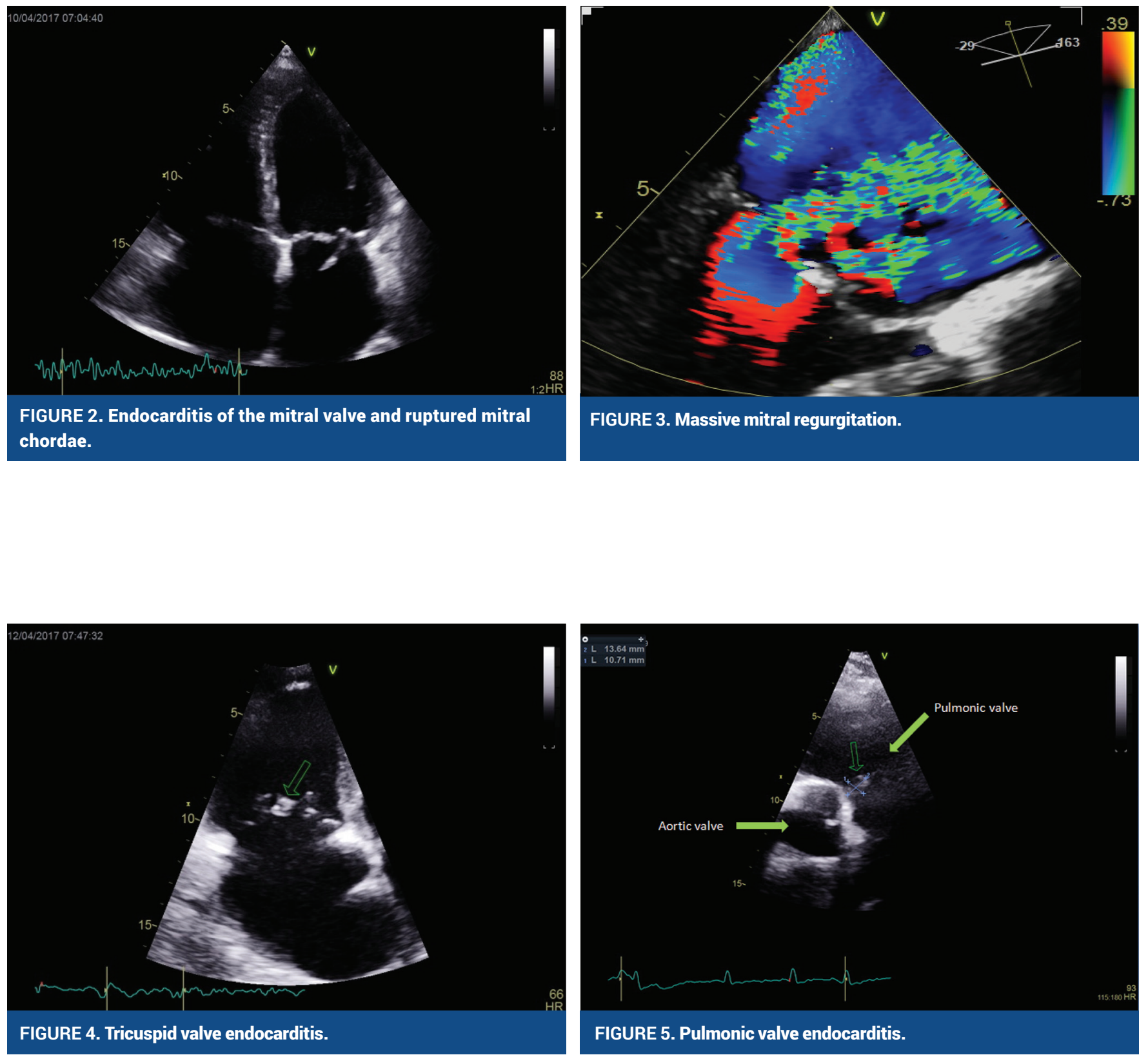

Conclusion: Severe anemia may be a sign of infective endocarditis and postpone the diagnosis due to initial gastroenterological and hematologic work-up enabling severe destruction of affected valves.

LITERATURE IIIIIIIIIIIIIIIIIIIIIIIIIIIIIIIIIIIIIIIIIIIIIIIIIIIIIIIIIIIIIIIIIIIIIIIIIIIIIIIIIIIIIIIIIIIIIIIIIIIIIIIIIIIIIIIIIIIIIIIIIIIIIIIIIIIIIIIIIIIIII

1. Thuny F, Giorgi R, Habachi R, Ansaldi S, Le Dolley Y, Casalta JP, et al. Excess mortality and morbidity in patients surviving infective endocarditis. Am Heart J. 2012 Jul;164(1):94-101. https://doi.org/10.1016/j.ahj.2012.04.003

2. Gubarev N, Separovic J, Gasparovic V, Jelic I. Successful treatment of mucormycosis endocarditis complicated by pulmonary involvement. Thorac Cardiovasc Surg. 2007 Jun;55(4):257-8. https://doi.org/10.1055/s-2006-924502

3. Klein M, Wang A. Infective endocarditis. J Intensive Care Med. 2016 Mar;31(3):151-63. https://doi.org/10.1177/0885066614554906

4. Kawada S, Kuriyama M, Kotani Y, Tsushima S, Tanabe A, Kioka Y. Nonbacterial thrombotic endocarditis involving all four cardiac valves. Asian Cardiovasc Thorac Ann. 2018 Jan;26(1):44-46. https://doi.org/10.1177/0218492317748091 